\title{
A new explanation for the Poggendorff illusion
}

\author{
LUCIA ZANUTTINI \\ Istituto di Psicologia, Universita di Trieste, Trieste, Italy
}

\begin{abstract}
Kanizsa $(1972,1974)$ has observed that the surface upon which a figure is amodally completed undergoes shrinkage. That observation is investigated here as a possible explanation of the Poggendorff illusion, on the assumption that the shrinkage of the surface behind the surface defined by the two vertical parallel lines results in displacement of the two visible segments of the oblique line. The first two experiments attempted to quantify the shrinkage of the amodal surface by measuring the enlargement of the vertical strip required to achieve perceived collinearity; the oblique lines intercepted the vertical strip at $45-$ and 30-deg angles. In both cases, the enlargement required to counterbalance the assumed amodal shrinkage was approximately $30 \%$. In the third experiment, the oblique line was rotated to the horizontal, and again the perceived shrinkage of the amodal surface was approximately $30 \%$. The application of this explanation to the Poggendorff illusion is discussed, as well as the relevance of this explanation to the common experimental finding that magnitude of the illusion is dependent upon the slope of the oblique line.
\end{abstract}

When an oblique line is intercepted by a blank area defined by two vertical parallel lines, the two resulting segments of the oblique line do not appear collinear. In Figure 1, for example, it seems that segment a does not line up with segment $b$, and vice versa; that is, a seems too high or $b$ seems too low. This is the Poggendorff illusion.

The magnitude of this illusion, which is more evident in children (Leibowitz \& Gwozdecki, 1967; Piaget, 1960; Pressey \& Sweeney, 1970; Vurpillot, 1963), depends on the size of the figure and on the distance from which it is observed (Sanford, 1868). Noncollinearity increases as the distance between the parallel lines decreases (Pressey, 1970). The illusion diminishes, or even disappears, if the figure is rotated so that the intercepted line becomes horizontal or vertical (Jacorzynski, 1963; Judd, 1899; Leibowitz \& Toffey, 1966; Velinski, 1925; Weintraub \& Krantz, 1971). It also decreases when any segment of the figure is removed (Goldstein \& Weintraub, 1972; Judd, 1899; Mayer-Hillebrand, 1942; Pressey \& Heyer, 1968; Weintraub \& Krantz, 1971).

Many explanations for the Poggendorff illusion have been offered. Some investigators believe that it is due to an error in angular perception (for instance, Chiang, 1968; Green \& Hoyle, 1963; Jacorzynski, 1963; and Piaget, 1960). Other investigators, such as Judd (1899), Pressey (1972), and Velinski (1925), believe that it is due to a perceptual error in evaluating linear dimensions.

An alternative interpretation of the illusion is proposed in this paper. The basic presumption of the interpretation is that in the Poggendorff figure the two oblique segments tend to join together, in an amodal way, ${ }^{1}$ across the space between the two vertical lines. From the observations of Kanizsa (1972), we know that the surfaces upon which amodally completed figures lie seem to shrink (see example in Figure 2). Kanizsa explains this phenomenon by assuming that in the region

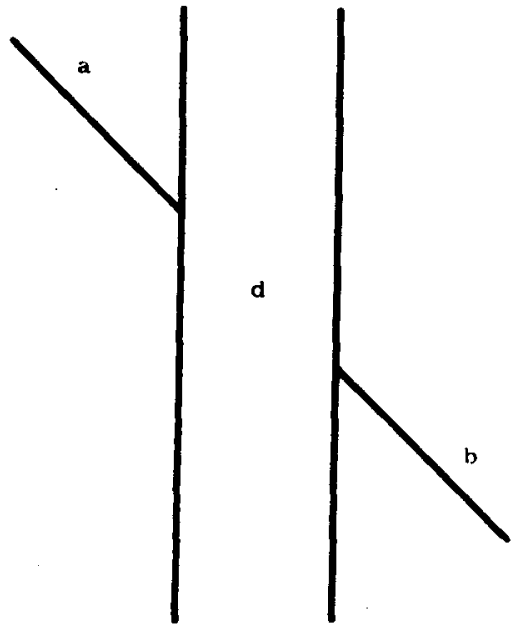

Figure 1. The Poggendorff display.

where there is a double representation (that is, the area shared by the black rectangle and the amodal portion of the white square behind) two surfaces are created. The energy of the stimulating figures is used preferentially to construct the front surface, while the rear surface has less energy at its disposal. The rear surface is perceived as smaller, and any pattern (in the case of the Poggendorff illusion, the oblique line) on that surface therefore seems to shrink. The explanation of this shrinkage is based on the general principles set forth by Metzger (1930) and Koffka (1935).

As a matter of fact, Kanizsa (1974) has measured some instances of apparent shrinkage. Using the stimuli shown in Figure 2, where a $30 \times 150 \mathrm{~mm}$ black band is superimposed on a $40 \times 40 \mathrm{~mm}$ white square, the apparent shrinkage of the square is approximately $4 \%$.

Whatever the explanation for the Kanizsa phenomenon might be, the phenomenon itself may be useful as an interpretation of the Poggendorff illusion. Let's look 

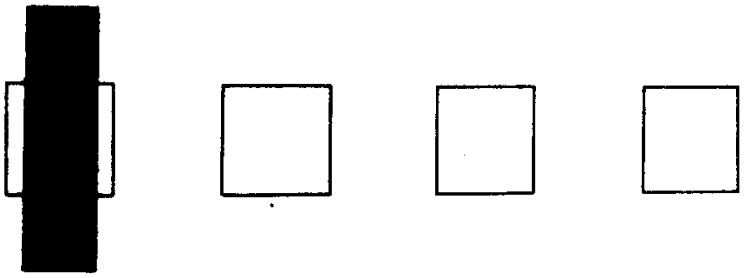

Figure 2. Amodal shrinkage in Kanizsa's situation.
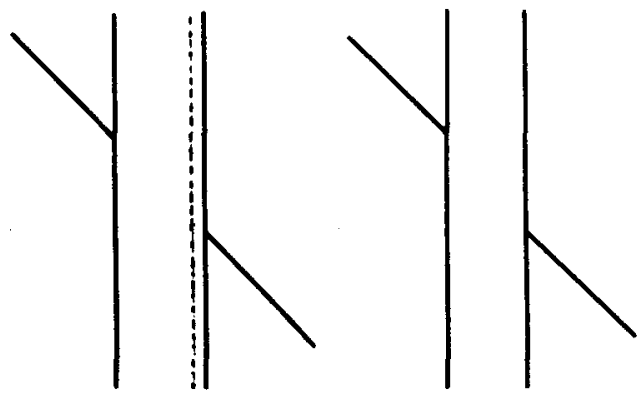

Figure 3. Deformation as a result of a geometrical shrinkage.
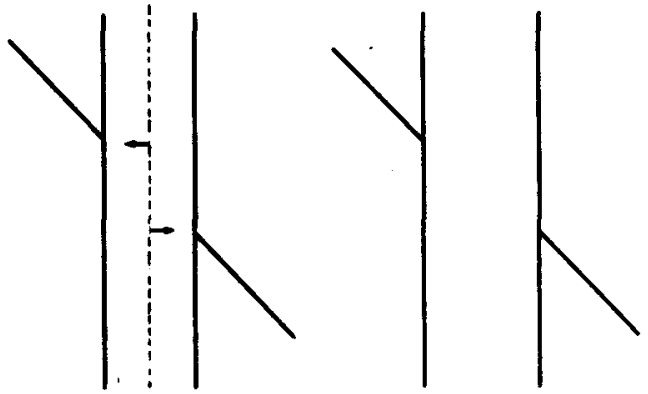

Figure 4. Perceived collinearity as a result of a geometrical enlargement.

once more at Figure 1. The lower segment of the oblique line is displaced downward with respect to perceived collinearity. If the surface between the parallel lines is actually shrunken or narrowed without alteration of the positions of the oblique segments (as would occur if one made a narrow fold within the parallel lines), the lower segment becomes much lower with respect to geometric collinearity (see Figure 3).

One might hypothesize that the same thing happens in the perceptual field: There is a shrinkage of the surface on which the line is amodally completed, and the two visible segments of the oblique line are displaced with respect to each other. Shrinkage of the rear surface, with consequent shrinkage of the amodal portion of the oblique line, could account very easily for the Poggendorff illusion.

On the other hand, collinearity should be restored if we could counterbalance the perceptual shrinkage. Of course, the only way to enlarge the rear surface is actually to enlarge the front surface.

\section{EXPERIMENT I}

I have tried to test this hypothesis experimentally.
Twenty naive adult subjects were shown a series of Poggendorff stimuli drawn in black ink on white cardboards, $26 \times 28 \mathrm{~cm}$, placed on the frontoparallel plane $80 \mathrm{~cm}$ from their eyes. One card contained the basic stimulus: Two visible portions, each $65 \mathrm{~mm}$ long, of a continuous oblique (45 deg) line, $1 \mathrm{~mm}$ wide, were interrupted by two vertical parallel lines, $1 \mathrm{~mm}$ wide, $30 \mathrm{~mm}$ apart, and $150 \mathrm{~mm}$ long. In this figure, the illusion is quite evident. The stimuli contained on the other cards retained the identical arrangement of the visible oblique segments but varied the distance $d$ between the parallel lines (see Figure 4). To make the series complete, two figures were included where $d$ was less than $30 \mathrm{~mm}$; the illusion is so strong that I thought it useless and confusing to present stimuli in which $\mathrm{d}$ was any less, and I also thought that the range of stimuli should be centered around the point of subjective equality if it could be anticipated. The $d$ values used in the experiment were $26,28,30$ (geometric collinearity), $32,34,36,38,40,42,44,46,48$, and $50 \mathrm{~mm}$. The aim was to obtain the amount of displacement necessary to obtain subjective collinearity; if apparent shrinkage underlies the illusion, then at the point of apparent collinearity physical expansion should equal apparent shrinkage. The series of cards was shown up and down the range of $d$ values both in free viewing and in tachistoscopic viewing (1.5- and $0.15-\mathrm{sec}$ durations) to equalize for all subjects conditions of inspection duration, distance, and brightness. ${ }^{2}$ Subjects were asked to indicate for each stimulus whether the two oblique segments were collinear or whether the "lower" one was much lower or much higher. The results obtained by the method of limits are shown in Table 1. As one can see, noncollinearity or deformation disappears when $d$ is increased $8.85 \mathrm{~mm}$ in free viewing, $10.42 \mathrm{~mm}$ in tachistoscopic viewing for $1.5 \mathrm{sec}$, and $9.67 \mathrm{~mm}$ in tachistoscopic viewing for $0.15 \mathrm{sec}$.

\section{EXPERIMENT II}

This experiment employed 20 new naive adult subjects under conditions essentially similar to those of Experiment I. The illusion figures were the same except that the slope of the oblique line was $30 \mathrm{deg}$ from the horizontal (instead of $45 \mathrm{deg}$ ). In this experiment, deformation was found to disappear when $d$ was increased approximately $9.10 \mathrm{~mm}$ (means: $8.87 \mathrm{~mm}$ in free viewing, $10.75 \mathrm{~mm}$ in tachistoscopic viewing for

Table 1

Means, Standard Deviations, and Percentage Enlargement of d Required to Achieve Perceived Collinearity When the Oblique Intercepts the Vertical at $45 \mathrm{Deg}(\mathrm{N}=20$ )

\begin{tabular}{lccc}
\hline Viewing Condition & Mean & SD & $\begin{array}{c}\text { Percent } \\
\text { Enlarge- } \\
\text { ment }\end{array}$ \\
\hline Free Viewing & 38.85 & 4.555 & 29.5 \\
Tachistoscopic $(1.5 \mathrm{sec})$ & 40.42 & 9.770 & 34.7 \\
Tachistoscopic $(.15 \mathrm{sec})$ & 39.67 & 7.455 & 32.2 \\
\hline
\end{tabular}

Note-Differencs between viewing conditions not significant. 
$1.5 \mathrm{sec}$, and $9.1 \mathrm{~mm}$ in tachistoscopic viewing for 0.15 ; see Table 2).

The results of Experiments I and II show that the distance, $d$, required to achieve perceived collinearity is independent of the slope of the oblique line. Within equivalent viewing conditions, the differences between the means of Experiments I and II are not significant. We can conclude from these data that the rear surface on which the oblique line is amodally completed shrinks by the same amount regardless of the slope of the line.

The magnitude of the Poggendorff illusion has usually been measured by raising the lower oblique segment or lowering the upper segment to restore collinearity (for example, see Leibowitz and Gwozdecki, 1967, and Pressey, 1970). Under those experimental conditions, the magnitude of the illusion has been found to vary with the slope of the oblique line, increasing as the oblique line departs from the horizontal. In the experiments reported here, I have found shrinkage to be independent of the slope of the oblique line. One might ask, then, how the same apparent shrinkage could produce different deformations for different orientations of the oblique. Perhaps the answer lies in the geometry of the figure. Consider Figure 5, where the amodal or subtended portions of the two Poggendorff figures are represented by dotted lines. The absolute length of the subtended portion of the oblique line is a direct function of the slope of that line; the greater the slope, the longer the portion that is subtended. If the area bounded by the vertical parallel lines is reduced, as we presume to occur in amodal perception, the resulting length of the subtended portion of the oblique line is directly proportional to its actual geometric length and hence directly proportional to its slope. For example, in the stimulus used in Experiment $I$, the slope of the oblique line is $45 \mathrm{deg}$ (see left figure in Figure 5); if the width between the vertical lines is reduced by $9 \mathrm{~mm}$, the length of the subtended oblique line is shortened by $12.7 \mathrm{~mm}$ and the resulting downward displacement of the emerging oblique line is $9 \mathrm{~mm}$. In the stimulus used in Experiment II (center figure in Figure 5), the slope of the oblique line is $30 \mathrm{deg}$; if the width between the vertical lines is reduced by $9 \mathrm{~mm}$, the length of the subtended oblique line is shortened by $11.5 \mathrm{~mm}$ and the resulting downward displacement of the emerging oblique line is $5.7 \mathrm{~mm}^{3}$ It should be plain from these

Table 2

Means, Standard Deviations, and Percentage Enlargement of d Required to Achieve Perceived Collinearity When the Oblique Intercepts the Vertical at $30 \mathrm{Deg}(\mathrm{N}=\mathbf{2 0})$

\begin{tabular}{lllc}
\hline \multicolumn{1}{c}{ Viewing Condition } & Mean & SD & $\begin{array}{c}\text { Percent } \\
\text { Enlarge- } \\
\text { ment }\end{array}$ \\
\hline Free Viewing & 38.87 & 6.391 & 29.5 \\
Tachistoscopic $(1.5 \mathrm{sec})$ & 40.75 & 6.829 & 35.8 \\
Tachistoscopic $(.15 \mathrm{sec})$ & 39.1 & 5.332 & 30.3 \\
\hline
\end{tabular}

Note-Differences between viewing conditions not significant.
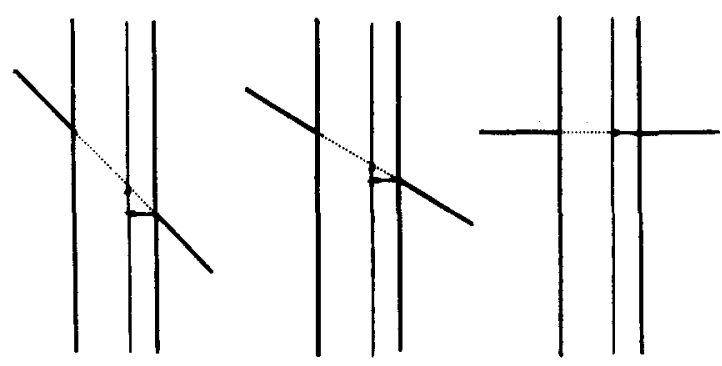

Figure 5. Deformation magnitude as a function of the tilt of the intercepted line.

examples that downward displacement or deformation of the oblique line is directly related to its slope when the reduction of the parallel width is constant.

If the surface upon which amodal completion occurs does shrink perceptually, the same geometric relationship should hold; that is, the apparent deformation of the lower emerging oblique segment should increase as the slope of the oblique line departs from the horizontal. And this is consistent with those experiments that have held constant the width between the parallel lines and measured collinearity by raising the lower oblique segment. On the other hand, the experiments reported here have shown that enlargement of the surface upon which amodal completion occurs produces results that are independent of the slope of the oblique line. But it might be objected that enlarging the amodal surface is synonymous to raising the lower segment-that the methods of measurement are really the same. This objection can be refuted by demonstrating that apparent shrinkage of the amodal surface occurs when an oblique line is not present.

\section{EXPERIMENT III}

In Experiments I and II, it was shown that increasing the distance, $d$, between the vertical lines from 30 to $39 \mathrm{~mm}$ (a 30\% increase) resulted in perceived collinearity. This finding tends to confirm the hypothesis that shrinkage of the amodal surface accounts for the Poggendorff illusion. The logic of amodal shrinkage and of geometry would also allow us to predict that a horizontal line lying on that surface would also shrink and would appear shorter when matched with an equal line that is completely visible.

The subjects in this experiment were 20 adults. The basic stimulus, drawn on a $62 \times 70 \mathrm{~cm}$ cardboard, was similar to the previously illustrated Poggendorff figures, except that the oblique line was rotated to a horizontal position (see right figure of Figure 5). The two vertical parallel lines were $150 \mathrm{~mm}$ long, $1 \mathrm{~mm}$ wide, and separated by $39 \mathrm{~mm}$. The horizontal line was $1 \mathrm{~mm}$ wide, and the exposed segments were each $65 \mathrm{~mm}$ long; these were aligned to represent a single horizontal line, $169 \mathrm{~mm}$ long, that "passed behind" the vertical strip. Each subject was shown a series of 17 horizontal line segments (viewing distance was $70 \mathrm{~cm}$ ), ranging in length 
from 153 to $185 \mathrm{~mm}$ in $2-\mathrm{mm}$ increments; 8 of these segments were shorter, 8 longer, and 1 equal to the geometric length of the intercepted horizontal line. The comparison segments were drawn on $25 \times 25 \mathrm{~cm}$ cardboards and presented one at a time at the lower right corner of the basic. figure. Each subject was asked to indicate for each segment whether it was longer, shorter, or equal to the horizontal line. The mean PSE was $160.25 \mathrm{~mm}, S D=10.59 \mathrm{~mm}, S E=2.43 \mathrm{~mm}$. The difference between the PSE and the geometric length of the horizontal line was 8.75 , roughly equivalent to the shrinkage value of d obtained in Experiments I and II..

\section{DISCUSSION}

Taken together, the results of these three experiments support the conclusion that shrinkage of the surface upon which amodal completion takes place can account for the Poggendorff illusion.

This explanation can be applied to other experimental situations in which this type of deformation occurs, such as interception of the oblique line by a circle (Virsu, 1968) or by an uneven figure such as the outline of Australia (Hotopf, 1966). In all these cases, the oblique line seems to pass behind an object and tends to be completed amodally. Because the amodal surface shrinks for lack of energy, it is perceived as slightly smaller than the intervening object, with the result that the portion of the oblique or transverse line that lies upon it is also slightly reduced in size. This explanation of the Poggendorff illusion offers a geometric rationale for the relationship found by many investigators between magnitude of the illusion and slope of the oblique line. The explanation also easily accounts for the finding that deformation increases with increases in width between the vertical parallel lines (Kanisza, 1974).

\section{REFERENCES}

Chiang, C. A new theory to explain geometrical illusions produced by crossing lines. Perception \& Psychophysics, 1968, 3, 174-176.

Goldstein, M. B., \& Weintraus, D. The parallel-less Poggendorff. Virtual contours put the illusion down but not out. Perception \& Psychophysics, 1972, 11, 353-355.

Green, R. T., \& HoYle, E. M. The Poggendorff illusion as a constancy phenomenon. Nature, 1963, 200, 611-621.

HotopF, W. H. N. The size-constancy theory of visual illusions. British Journal of Psychology, 1966, 57, 307-317.

JACORZYNSxI, G. K. Brain dynamism as reflected in illusions. Genetic Psychological Manographs, 1963, 68, 3-47.

JudD, C. A study of geometrical illusions. Psychological Review, 1899, 6, 241-261.

Kanizsa, G. Schrumpfung von visuellen Feldern bei amodaler Erganzung. Studia Psychologica, 1972, 14, 208-210.

Kanizsa, G. Amodal completion and phenomenal shrinkage of surfaces in the visual field. Reports from the Institute of Psychology, University of Trieste, 1974.
Kofrka. K. Principle's of gestalt psychology. New York: Harcourt Brace, 19.35.

Lelbowitz, H. W., \& Gwozdecki, J. The magnitude of the Poggendortf illusion as a function of age. Child Development, $1967,38,573-580$.

Leinowitz, J. W., \& Toffey, S. The effect of rotation on the magnitude of the Poggendortif illusion. Vision Research, 1966, 6 , 101-103.

Mayer-Hillebrand, F. Die geometrisch-optischen Tauschungen als Auswirkungen allgemein feltender Wahrnehmungesetze. Zeitschrifite für Psychologie, 1942, 152, 126.210.

Metzger, W. Zur Phänomenologie des homogenen Ganzfeldes. Psychologische Forschung, 1930, 13, 6-29.

MichotTe, A., \& Burke, L. Une nouvelle enigme de la psychologie de la perception: Lc 'donne amodal' dans l'experience sensorielle. In Causalite, permunence et realite' phenomenules. Louvain, France: Publications Universitaires, 1962.

Michotte, A., Thines, G., \& Crabee, G. Die amodalen Erganzungen von Wahrnehmungs strukturen. In Handbuch uler psychologie. Gottingen: Hogrefe, 1966.

Piaget, J. Les mecanismes perceptifs. Paris: P.U.F., 1960.

Pressey, A. W. An explanation of effect of tilt on the Poggendortf illusion. Psychonomic Science, 1970, 18, 347.

Pressex, $A$. W. The assimilation theory of geometric illusions: An additional postulate. Perception \& Psychophysics, 1972. 11, 28-30.

Pressey, A. W., \& Heyer, K. Observations on Chiang's 'new' theory of geometrical illusions. Penception \& Psychophysics, $1968,6,101 \cdot 103$.

Pressey, A. W., \& Sweeney, $O$. Age changes in the Puggendorff illusion as measured by a method of production. Psychonomic Science, 1970, 19, 99.100.

SANFORD, E. C. A course in experimental psychology. Boston: Heath, 1868.

Velinski, S. Explication physiologique de l'illusion de Poggendortf. Année Psychologique, 1925, 26, 107-116.

Virsu, V. Geometric illusions as categorization effects: A system of interpretation. Helsinki: Suomalinen Tiedeakatemia, 1968.

Vurpillot, E. L'organisation perceptive, son role dans levolution des illusions optico-geometriques. Paris: Vrin, 1963.

Weintraua, D., \& Krintz, D. The Poggendorff illusion: Amputations, rotations, and other perturbations. Penception A Psychophysics, 1971, 10, 257-264.

\section{NOTES}

1. When an object is partially hidden by another object, it may appear to continue behind it. The partially hidden object is perceived as complete even though sensory inputs from parts of it are lacking. This phenomenon is referred to as "amodal completion" (Michotte \& Burke, 1962; Michotte, Thines, \& Crabbe, 1966 ), and the perceptually completed figure is called the amodal portion.

2. In free viewing, it was impossible to control the illumination of the room and the exact distance of the subjects' eyes from the display. In tachistoscopic viewing, luminance and viewing distance were controlled.

3. Vertical displacement of the oblique is equal to the shrinkage times the tangent of the angle of the oblique from the horizontal, $\mathrm{VD}=\mathrm{S}(\tan \theta)$.

(Received for publication April 2, 1975; revision accepted April 14, 1976.) 